\title{
Field evaluation of natural human odours and the biogent-synthetic lure in trapping Aedes aegypti, vector of dengue and chikungunya viruses in Kenya
}

Eunice A Owino ${ }^{1,2}$, Rosemary Sang ${ }^{1,3}$, Catherine L Sole ${ }^{2}$, Christian Pirk ${ }^{2}$, Charles Mbogo ${ }^{4}$ and Baldwyn Torto ${ }^{1 *}$

\begin{abstract}
Background: Methods currently used in sampling adult Aedes aegypti, the main vector of dengue and chikungunya viruses are limited for effective surveillance of the vector and accurate determination of the extent of virus transmission during outbreaks and inter - epidemic periods. Here, we document the use of natural human skin odours in baited traps to improve sampling of adult Ae. aegypti in two different endemic areas of chikungunya and dengue in Kenya - Kilifi and Busia Counties. The chemistry of the volatiles released from human odours and the Biogent (BG)-commercial lure were also compared.

Methods: Cotton socks and T-shirts were used to obtain natural human skin volatiles from the feet and trunk of three volunteers (volunteers 1 and 2 in Kilifi and volunteers 2 and 3 in Busia). Using Latin square design, we compared the efficacies of BG sentinel traps baited with carbon dioxide plus (a) no bait, (b) human feet volatiles, (c) human trunk volatiles each against (c) a control (Biogent commercial lure) at the two sites. Coupled gas chromatography-mass spectrometry (GC-MS) was used to identify and compare candidate attractants released by the commercial lure and human odours.
\end{abstract}

Results: Ae. aegypti captured in the trap baited with feet odours from volunteer 2 and trunk odours from the same volunteer were significantly higher than in the control trap in Busia and Kilifi respectively, [IRR $=5.63,95 \%$ Cl: $1.15-28.30$, $\mathrm{p}=0.030]$ and [IRR $=3.99,95 \% \mathrm{Cl}: 0.95-16.69, \mathrm{p}=0.049]$. At both sites, Ae. aegypti captures in traps baited with either the feet or trunk odours from volunteers 1 and 3 were not significantly different from the control. Major qualitative differences were observed between the chemical profiles of human odours and the commercial BG-lure. Aldehydes, fatty acids and ketones dominated human odour profiles, whereas the BG-lure released mainly hexanoic acid.

Conclusions: Our results suggest that additional candidate attractants are present in human skin volatiles which can help to improve the efficacy of lures for trapping and surveillance of Ae. aegypti.

Keywords: Aedes aegypti, Dengue, Chikungunya, Human odour, Mosquito, Traps

\footnotetext{
* Correspondence: btorto@icipe.org

'International Centre of Insect Physiology and Ecology, P.O BOX 30772-00100,

Nairobi, Kenya

Full list of author information is available at the end of the article
} 


\section{Background}

Aedes aegypti is one of the most important disease vectors worldwide. It is the principal vector of dengue [1], chikungunya [2] and Yellow fever [3] viruses. Among arboviral diseases, dengue fever has been reported to cause more human morbidity and mortality than any other arthropod-borne viral disease [4,5]. It is estimated that each year, 50-100 million dengue infections and several hundred thousand cases of dengue hemorrhagic fever (DHF) occur, depending upon epidemic activity [6,7]. In the past 10 years, there have been sporadic outbreaks of chikungunya fever along the Kenyan coast and the Indian Ocean islands of the Comoros, Seychelles, Reunion and Mauritius [8-11]. Additionally, in Kenya, a dengue outbreak was reported in Mandera County in September 2011 [12] and more recently in Mombasa County in May 2014 [13].

The increase in the emergence of dengue and chikungunya fever has been attributed to climate change [10] urbanization $[4,5,14,15]$ and globalization $[4,5,16]$, amongst other factors. Consequently, the projected trends of continued global warming, urbanization and globalization will ensure that the incidence of these diseases will increase, especially if interventions are not forthcoming $[15,4]$. Presently, there is no registered vaccine for prevention of dengue and chikungunya viruses which makes vector control the only available target for disease control and prevention. Under the circumstances, it is important to monitor the viruses and vector populations in endemic areas to understand their ecology before implementing appropriate and timely intervention. This therefore, calls for efficient surveillance and monitoring tools that will give reasonably accurate measures of disease and vector abundance data to guide decision on disease control measures.

The simplest and most effective sampling method for adult Ae. aegypti has been human-landing collections $[17,18]$. Although effective in determining the exact anthropophilic species composition, human attack rate, and potential for disease transmission, renders this method inappropriate since it exposes the collectors to a degree of risk to infection and is also labour intensive. On the other hand, the popularly used mosquito surveillance trap, the Centers for Disease Control and Prevention (CDC) light trap [19] is virtually ineffective in sampling the day biting Ae. aegypti as it targets nocturnal host seeking species [17].

Odour-baited traps provide an effective means for monitoring insect populations. A recent study demonstrated the efficacy of an odour-baited trapping system for mosquito vectors of Rift Valley Fever virus [20,21]. The Biogent (BG) sentinel trap baited with synthetic human skin compounds consisting of lactic acid, ammonia, and caproic acid (hexanoic acid) was used for sampling Ae. aegypti [22]. However, considerable reports have suggested that synthetic odours [23-25] or extracted human component blends [26] do not attract Ae. aegypti at a level comparable to natural human odours. Evaluating the effectiveness of the BG synthetic lure against natural human odours at different sites would therefore be critical for its wide scale use in disease vector control, especially Aedes $s p$ vectors of chikungunya and dengue viruses.

In this study our objective was to compare the attractiveness of the commercial BG lure with natural human odours from two different sources, feet and trunk, in trapping Ae. aegypti in the field. We carried out this study in two dengue and chikungunya virus endemic areas in Kenya. Since mosquitoes are attracted to volatiles released from the different treatments, we compared the composition of these volatiles in order to identify the candidate attractants from the different treatments.

\section{Methods}

\section{Study sites}

The study areas were Kilifi County at the Kenyan Coast and Busia County in Western Kenya (Figure 1). Previous seroprevalence studies had shown that dengue infection was prevalent in the Malindi area of Kilifi, with chikungunya infection occurring in Busia County [27]. The most recent outbreak of chikungunya also occurred at the coast [9].

Kilifi County has an average annual rainfall of $950 \mathrm{~mm}$. The rainfall pattern is bimodal; the long monsoon rains (April - July) and the short rains (October- December). The annual temperatures range from a minimum of $21^{\circ} \mathrm{C}$ and a maximum of $32^{\circ} \mathrm{C}$. Busia County on the other hand has an average annual rainfall of $1500 \mathrm{~mm}$. The rainfall pattern is also bimodal; long rains (March - June) and short rains between (October -December). The temperatures range from a minimum of $14^{\circ} \mathrm{C}$ and a maximum of $30^{\circ} \mathrm{C}$.

In Busia County, traps were set up in villages in the rural areas namely Obekai (30.875 N, $3412.293 \mathrm{E})$, Kamosin (0 31.530 N, 34 13.125E) and Kalwa (0 30.190 N, $3414.020 \mathrm{E})$. These are locations that occur at approximately $1189 \mathrm{~m}$ above the sea level (ASL). The main vegetation in these areas consists of large, tall eucalyptus trees that form thick canopies. The local inhabitants are mainly small-scale farmers growing maize, millet and cassava food crops while a few grow sugarcane and coffee as cash crops. They also keep a few animals mainly cattle, sheep, goats, pigs, chicken and guinea fowls.

In Kilifi county, traps were set up at two sites located in the urban area; Kenya medical research institute (KEMRI) campus in Kilifi (3 37.800 S, $3951.483 \mathrm{E}$ ) and Mnarani estate (3 38.368 S, 3950.824 E), while the other site was in the Kaya Kauma forest (3 37.183 S, 3944.167 E). These are locations that occur at approximately $30.5 \mathrm{~m}$ 


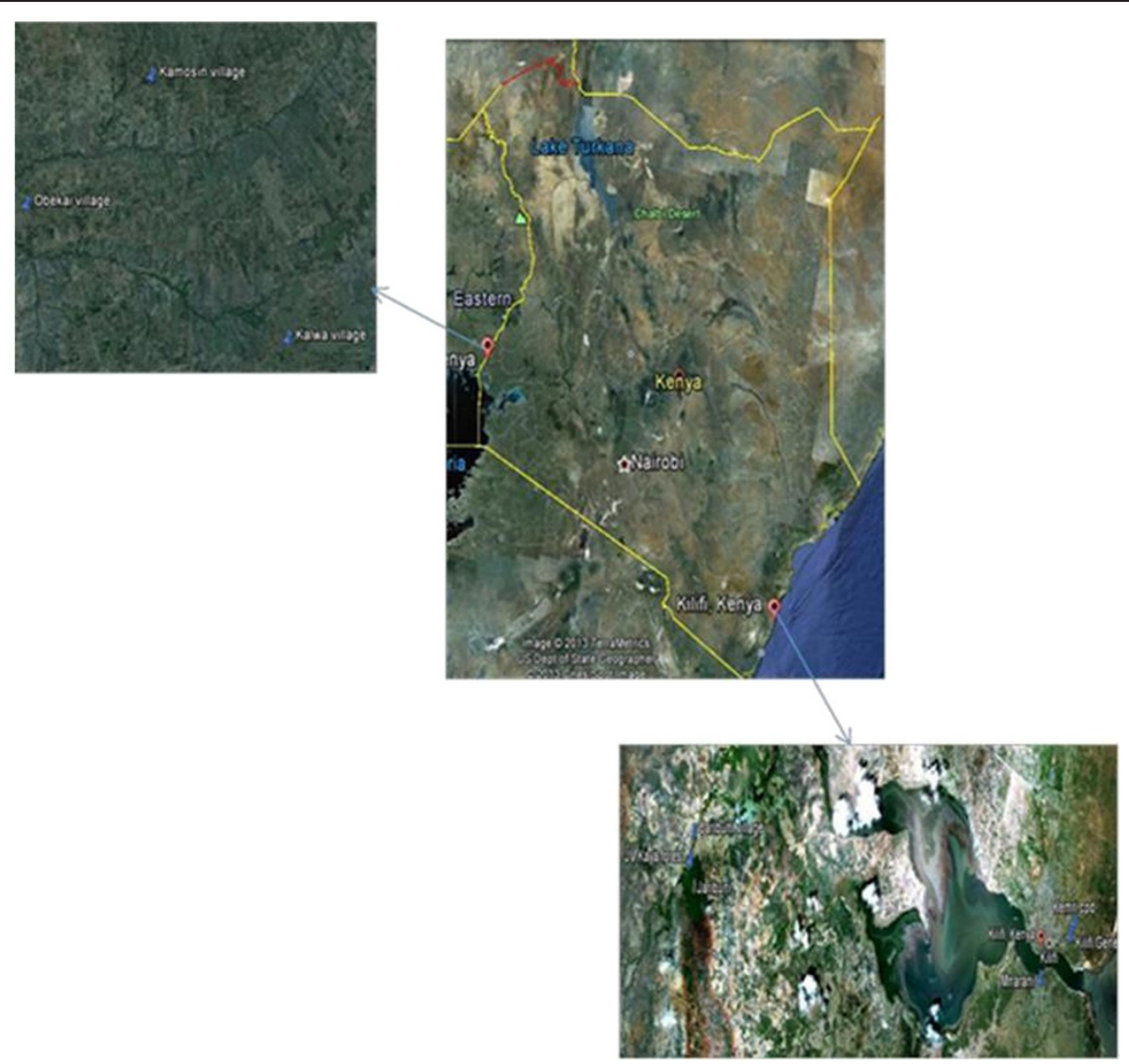

Figure 1 The study sites; Kilifi district in the coast and Busia district in western Kenya.

ASL. The inhabitants in the urban area mainly engage in small businesses or work in offices. They also grow maize, cassava and sweet potatoes and keep a few animals, mainly goats.

The traps were set up during the wet seasons at both sites. In Kilifi, the traps were set up in April 2012 and June 2012 while in Busia they were set up in December 2012 and April 2013.

\section{Study design}

A Latin square design was used. At each sampling location, Kilifi or Busia, the efficacy of the BG sentinel trap baited with carbon dioxide plus (i) the BG commercial lure, (ii) cotton socks or T-shirts worn by two volunteers in Kilifi and two volunteers in Busia and (iii) no bait, were set.

\section{Odour collection and mosquito sampling with odour-baited traps}

Odours were obtained from the feet and trunk of three male volunteers (volunteers 1, 2 and 3) aged between 25-50 years. Trunk and feet odours from volunteer 1 were used as baits in Kilifi and that from volunteer 3 in Busia while that from volunteer 2 were used in both
Kilifi and Busia. The same individuals were involved throughout the study. Socks and T-shirts worn by volunteers 1 and 2 were used to sample mosquitoes in Kilifi while those worn by volunteers 2 and 3 were used to sample mosquitoes in Busia. The volunteers were requested to put on new, clean, $100 \%$ cotton socks and T-shirts (Lux Industries Ltd 39 K.K Tagare st, Kolkata700-007) for 18 hrs daily to trap odours from their feet and trunk for nine 12 days. After 18 hrs each day, the volunteers removed the socks and $\mathrm{T}$-shirts which were used to bait BG sentinel traps by hanging them on the rails of the BG sentinel trap inner structure as shown in (Figure 2). During this period and prior to wearing the socks and T-shirts, the volunteers were provided with an odourless soap daily for bathing and were requested to avoid the use of deodorants and/or perfumes.

\section{Mosquito sampling with odour baited traps}

Four different sites were randomly chosen around homesteads after obtaining oral consents from the homestead heads. Four BG sentinel traps baited with the commercial lure, socks or T-shirts worn by the different volunteers and no baits were randomly set up at each of the four sites with a distance of at least one hundred $(100 \mathrm{~m})$ between 


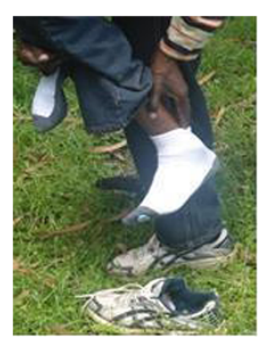

a

h

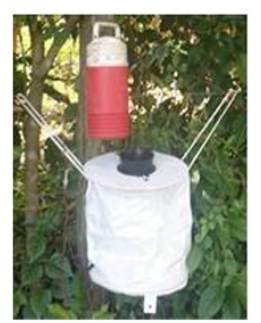

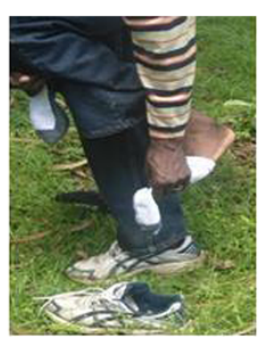

b

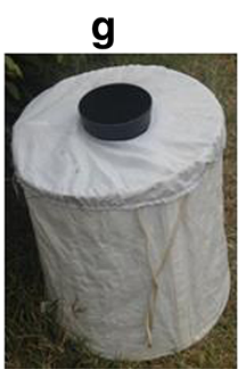

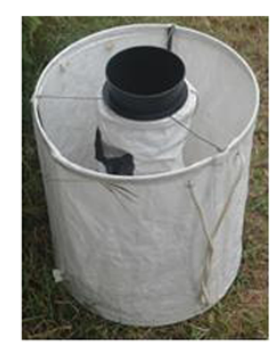

C

f

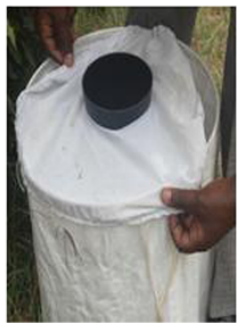

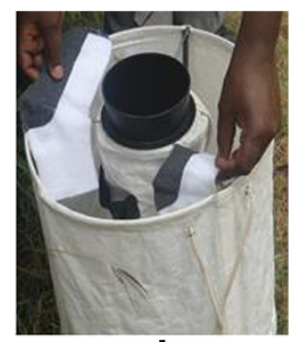

d

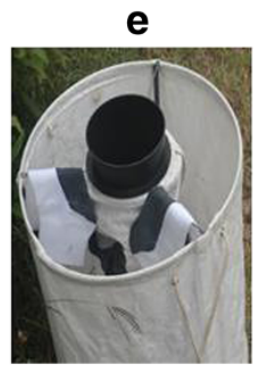

Figure 2 The BG sentinel traps were baited with socks and set up in Busia and Kilifi counties of Kenya. Assembly follows steps a-h

traps. The traps were hung at $0.2 \mathrm{~m}$ above the ground and attached to each was a Bioquip igloo that dispensed carbon dioxide in the form of dry ice (Figure 2). To account for positional effects, traps were rotated every experimental day. This was repeated for 12 days.

Because some sites were at a distance of up to $40 \mathrm{~km}$ apart in both Busia and Kilifi, traps were set up at each site at different times of the day and left to run for 24 hrs. Mosquitoes were then collected and transported to the laboratory where they were freeze-killed and identified under a dissecting microscope to species level using morphological keys [28-31]. Mosquitoes were categorized as engorged when blood fed or gravid based on observation of their abdominal condition as described in the WHO Manual [32]. Daily mosquito counts per trap were recorded for each mosquito species.

\section{Collection and analysis of volatiles}

In order to analyze and compare the composition of volatiles released by the commercial lure and the human odours, headspace volatiles from the commercial BG-lure and from the three volunteers' feet and trunks were collected using solid phase micro- extraction (SPME) technique for $6 \mathrm{hrs}$ at room temperature. Odours were also trapped and analyzed from unused $100 \%$ cotton socks and T-shirts, which acted as control. The odours were adsorbed on $75 \mu \mathrm{m}$ carboxen-poly dimethyl siloxane (CAR/PDMS) and 50/30 $\mu \mathrm{m}$ Divinyl benzene/ Carboxen/ Poly dimethyl siloxane (DVB/CAR/ PDMS) (Supelco: Sigma-Aldrich Pty Ltd, Bellefonte, USA) fibers. The fibers were each conditioned at $270^{\circ} \mathrm{C}$ for 1 hr before use.
After extraction the SPME fibers were injected into the gas chromatography - mass spectrometry (GC-MS) and mass selective detector (MSD) system consisting of a model HP 7890A gas chromatograph, a 5975 Mass spectrometer with a triple Axis detector and an Agilent ChemStation data system. The GC column was a Carbowax HP-20 with 20\% Carbowax stationary phase (30 $\mathrm{m} \times 250 \mu \mathrm{m} \times 0.25 \mu \mathrm{m}$ film thickness). The carrier gas was helium with a column head pressure of $8.8271 \mathrm{psi}$ and flow rate of $1.2 \mathrm{ml} / \mathrm{min}$. Inlet temperature was $220^{\circ} \mathrm{C}$ and mass selective detector temperature was $230^{\circ} \mathrm{C}$. The oven temperature was held at $35^{\circ} \mathrm{C}$ for $5 \mathrm{~min}$, a rise of $10^{\circ} \mathrm{C} \mathrm{min}{ }^{-1}$ to a final temperature of $220^{\circ} \mathrm{C}$, which was held for $20.5 \mathrm{~min}$. The identity of compounds in the volatiles was determined by comparison with references from mass spectral libraries (NIST05, Agilent Technologies [NIST database, G1033A, revision D.05.01, ChemStation data system (G1701EA, version E.02.00) and SPME analysis of a mixture of the authentic compounds. Each compound in the authentic mixture was $100 \mathrm{ng} / \mathrm{ul}$.

The chemicals were ; hexanoic acid, hexanal, octanal, nonanal, decanal, 6-methyl-5-hepten-2-one, geranylacetone (Sigma-Aldrich Chemie GmbH, Germany), 3-methylbutyric acid and 2-methylpropionic acid (Sigma-Aldrich Corporation, 3050 Spruce Street, St. Louis, Missouri 63103 USA). Purities of the compounds ranged between 95\% and 99\%.

\section{Data analysis}

The daily mosquito counts in the different traps were subjected to negative binomial regression following the generalized linear models (GLM) procedures in $\mathrm{R}$ 3.1.0 [33]. The BG commercial lure baited trap was used as 
the reference category. The incidence rate ratios (IRR) a likelihood measure that mosquito species chose other treatments instead of the control - and corresponding P-values were estimated. The chi-square test was applied to evaluate differences between proportions of male and female Ae. aegypti per trap and differences between proportions of fed and gravid mosquitoes per a treatment trap and the control. The tests were performed at $5 \%$ significance level.

\section{Ethics statement}

The study was approved by the national ethics review committee based at the Kenya Medical Research Institute (KEMRI) and informed consent was obtained from each of the participants.

\section{Results}

\section{Mosquito sampling with odour baited traps}

A total of 1,989 Ae. aegypti were collected, 1,805 in Kilifi and 184 in Busia. Overall, we found a significant variation in trap captures of Ae. aegypti based on location $\left[\mathrm{X}^{2}=332.35\right.$, d.f $\left.=1, \mathrm{p}<0.001\right]$, with higher trap captures recorded in Kilifi than Busia for the same number of days $[\mathrm{IRR}=9.81,95 \% \mathrm{CI}: 5.8-16.6, \mathrm{p}<0.001]$.

In Kilifi, the trap baited with trunk volatiles from volunteer 2 trapped a significantly higher number of Ae. aegypti than the control (Figure 3), $[\mathrm{IRR}=3.99$,
95\% CI: 0.95-16.69, $\mathrm{p}=0.049]$, while the trap baited with trunk volatiles from volunteer 1 and the trap baited with carbon dioxide only captured fewer of this mosquito species than the control [IRR $=0.92,95 \% \mathrm{CI}: 0.22-3.87$ ] and $[\mathrm{IRR}=0.691, \mathrm{CI}: 0.16-2.92]$ respectively (Table 1$)$. At the same site, the trap baited with feet volatiles from volunteer 2 captured more Ae. aegypti than the control trap (Figure 3), [IRR $=2.43$, 95\% CI: $0.71-8.29]$, while both the trap baited with feet volatiles from volunteer 1 and the trap baited with carbon dioxide only captured fewer Ae. aegypti than the control trap [IRR $=0.86,95 \% \mathrm{CI}$ : $0.25-2.93$ ] and [IRR $=0.32,95 \%$ CI: $0.09-1.10$ ] respectively (Table 1).

In Busia, the traps baited with foot odour from volunteer 2, foot odour from volunteer 3 and carbon dioxide only captured more Ae. aegypti than the control (Table 1), with the trap baited with feet volatiles from volunteer 2 trapping significantly more Ae. aegypti than the control trap (Figure 3) $[\mathrm{IRR}=5.63,95 \% \mathrm{CI}$ : 1.15 - 28.30, $\mathrm{p}=0.030]$. The same trend was observed when traps baited with the same volunteer's trunk volatiles were compared with the control (Figure 3). The order of performance was; volunteer 2 [IRR $=3.00,95 \%$ CI: $0.18-6.68$ ], carbon dioxide only [IRR $=1.16,95 \% \mathrm{CI}$ : $0.192-6.98]$ and volunteer 3 [IRR $=1.11$, 95\% CI: 0.51-17.61] (Table 1).

When proportions of male and female Ae. aegypti captured per trap were compared, a significantly higher

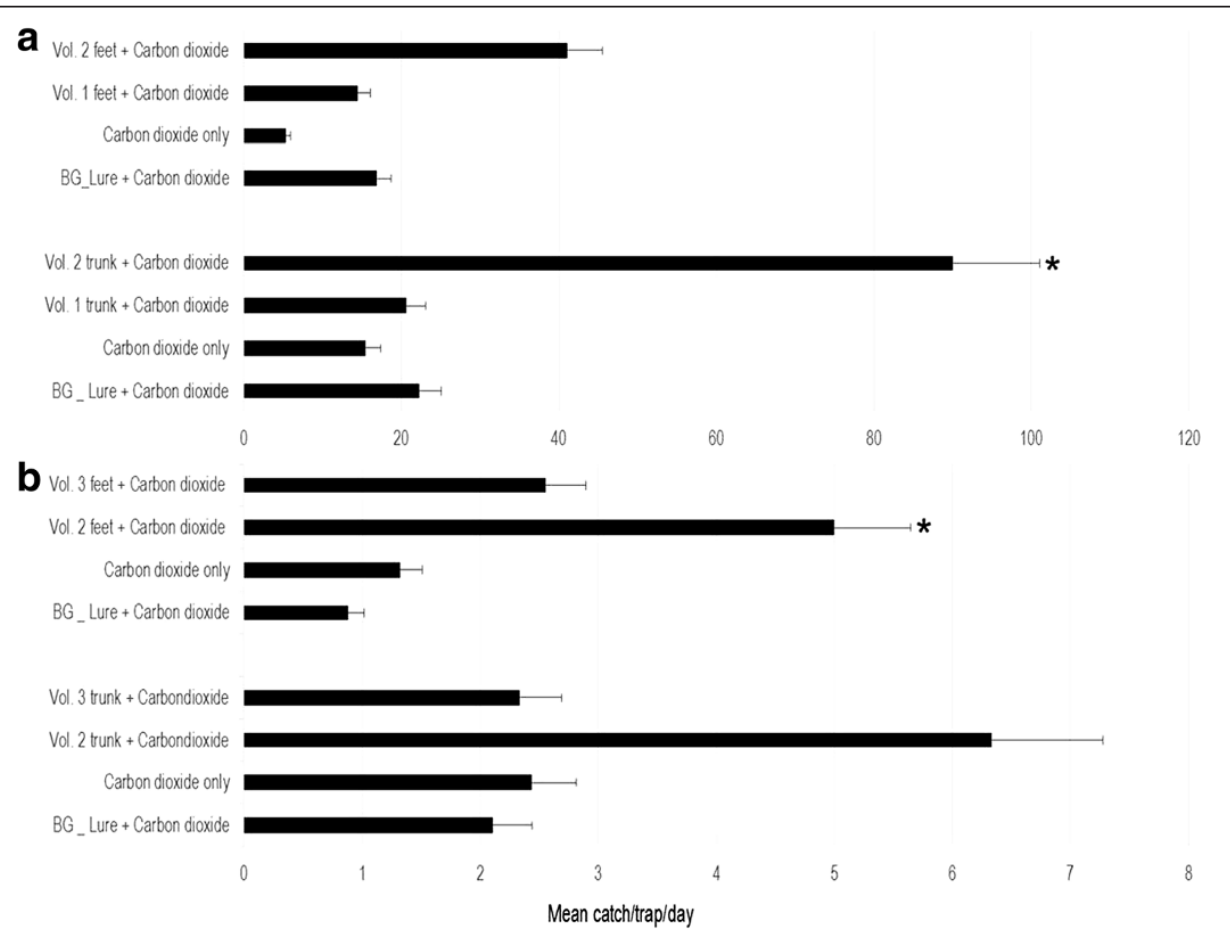

Figure 3 The mean number/day and \pm S.E of Aedes aegypti captured by the various BG sentinel traps baited with different baits in Kilifi and Busia counties. The different panels show comparisons at the two locations; Panel a -Kilifi and Panel b- Busia. Asterisks indicate that the mean catch of the trap is significantly different from the mean catch of the control trap (Biogent's commercial lure baited trap). Error bars indicate standard error of the mean. 
Table 1 Comparisons of mosquito collections by BG sentinel traps baited with feet and trunk odours from volunteer 1, volunteer $\mathbf{2}$ and carbon dioxide in Kilifi county and from volunteer 2, volunteer 3 and carbon dioxide in Busia county relative to the control (Biogents commercial lure baited BG sentinel trap) trap

\begin{tabular}{|c|c|c|c|c|c|c|}
\hline Site & Treatment & $\operatorname{IRR}(95 \% \mathrm{CI})$ & $P$ value & Treatment & $\operatorname{IRR}(95 \% \mathrm{CI})$ & $P$ value \\
\hline Kilifi & Carbon dioxide & $0.69(0.16-2.92)$ & 0.602 & Carbon dioxide & $0.32(0.09-1.10)$ & 0.064 \\
\hline Kilifi & Volunteer 1 trunk odour & $0.92(0.22-3.87)$ & 0.906 & Volunteer 1 feet odour & $0.86(0.25-2.93)$ & 0.790 \\
\hline Kilifi & Volunteer 2 trunk odour & $3.99(0.95-16.69)$ & $0.049 *$ & Volunteer 2 feet odour & $2.43(0.71-8.29)$ & 0.143 \\
\hline Busia & Carbon dioxide & $1.16(0.19-6.97)$ & 0.867 & Carbon dioxide & $1.50(0.28-8.04)$ & 0.627 \\
\hline Busia & Volunteer 2 trunk odour & $3.00(0.52-17.61)$ & 0.203 & Volunteer 2 feet odour & $5.63(1.15-28.30)$ & $0.030^{*}$ \\
\hline Busia & Volunteer 3 trunk odour & $1.10(0.18-6.67)$ & 0.909 & Volunteer 3 feet odour & $2.87(0.57-14.80)$ & 0.192 \\
\hline
\end{tabular}

Estimated incidence rate ratio (IRR); confidence interval $(\mathrm{Cl})$ and corresponding P-values based on comparison to the $\mathrm{BG}$ lure following generalized linear model (GLM) with negative binomial error structure and log link in R 3.1.0 software. The IRR for the control is 1 ; values above this indicate better performance while values below indicate under performance relative to the control. Asterisks on $\mathrm{p}$ values indicate significant difference with the control.

number of males were captured by the trap baited with trunk odours from volunteer $1\left[\mathrm{p}<0.001, \mathrm{X}^{2}=20.92\right.$, d.f $=1$ ] (Table 2). A further comparison between the proportions of fed and gravid Ae. aegypti per treatment trap and the control trap showed that traps baited with foot odours from volunteer 1 , volunteer 2 and volunteer 3 captured more gravid Ae. aegypti than the control (Table 2).

Although data analysis was only limited to Ae. aegypti, other mosquito species including Culex quinquefasciatus, Culex annulioris, Anopheles gambiae and Anopheles funestus also occurred in large numbers in the traps at both sites. There were also small numbers of Anopheles coustanii in both Kilifi and Busia, Mansonia uniformis, Mansonia africana, Eretmapodites chrysogaster group, Culex poicilipes, Coquillettidia faseri, Aedes metallicus, Aedes woodi and Aedes bromeliae in Kilifi.

\section{Analysis of volatiles}

The BG-lure, trunk and feet of human volunteers all released volatiles that attracted Ae. aegypti into traps. Analysis of the volatiles showed major qualitative and quantitative differences in the chemical profiles between trunk and foot odours and the commercial lure. Aldehydes and fatty acids dominated the volatiles released by human odours, which varied between individual volunteers, whereas hexanoic acid was the major component released by the BG lure (Table 3 ).

\section{Discussion}

We observed that Ae. aegypti captures in Kilifi were generally higher than in Busia. Several factors could have played a role in this difference. Firstly, Ae. aegypti is a known container breeding mosquito [34,35] and since the sampling sites in Kilifi were mainly in an urban area, there is the likelihood for the mosquito to find more of this type of breeding site in this area. On the other hand, the Busia sampling sites which are rural would provide the opposite situation. Secondly, Kilifi being an old urban center, with older and abundant houses that could serve as suitable breeding sites for this mosquito species. Walker et al., 2008 [36] observed that older houses with mature vegetation, and objects collected in the yard tended to have higher densities of Ae. aegypti eggs than newer houses. Thirdly, previous studies of $A e$. aegypti in the Kenyan coast observed that they are highly

Table 2 Comparisons of Ae aegypti proportions per trap by sex and abdominal status with corresponding catch indices $(\mathrm{Cl})$

\begin{tabular}{|c|c|c|c|c|c|c|c|c|c|c|}
\hline Bait & Total & $\sigma^{\top}$ Proportion & Q Proportion & P-values & Fed proportion & $\mathrm{Cl}$ & P-values & Gravid proportion & $\mathrm{Cl}$ & P-values \\
\hline BG-Lure & 191 & $52.4^{\mathrm{a}}$ & $47.6^{a}$ & 0.412 & 5.5 & 1 & - & 2.2 & 1 & - \\
\hline Carbon dioxide only & 166 & $45.8^{a}$ & $54.2^{\mathrm{a}}$ & 0.153 & 2 & 0.3 & 0.191 & 3.3 & 1.3 & 0.951 \\
\hline Volunteer 2 socks & 415 & $41.9^{\mathrm{b}}$ & $58.1^{\mathrm{a}}$ & $<0.001$ & 0.8 & 0.2 & $0.040^{*}$ & 1.2 & 1.3 & 1 \\
\hline Volunteer 2 T-shirt & 858 & $52.0^{\mathrm{a}}$ & $48.0^{\mathrm{a}}$ & 0.112 & 0.2 & 0.2 & $0.001^{*}$ & 1.2 & 2.5 & 1 \\
\hline Volunteer 1 socks & 130 & $43.9^{a}$ & $56.1^{\mathrm{a}}$ & 0.061 & 0 & 0 & $<0.001^{*}$ & 2.7 & 1 & 1 \\
\hline Volunteer 1 T-shirt & 185 & $62.2^{b}$ & $37.8^{\mathrm{a}}$ & $<0.001$ & 0 & 0 & $<0.001^{*}$ & 0 & 0 & 0.252 \\
\hline Volunteer 3 socks & 23 & $43.5^{\mathrm{a}}$ & $56.5^{\mathrm{a}}$ & 0.562 & 0 & 0 & $<0.001^{*}$ & 7.7 & 4.5 & $0.043^{*}$ \\
\hline Volunteer 3 T-shirt & 21 & $0^{b}$ & $100^{\mathrm{a}}$ & $<0.001$ & 0 & 0 & $<0.001^{*}$ & 0 & 0 & 0.256 \\
\hline
\end{tabular}

Proportions following each other in the rows with different letters ( $a$ and $b$ ) are significantly different from each other. Asterisks on $p$ values indicate significant difference with the control. The P-values are based on pair-wise comparison following chi-square goodness-of-fit in R 3.1.0 software.0'-Male Ae. aegypti, O-female Ae. aegypti. 


\begin{tabular}{|c|c|}
\hline Volatile source & Major compounds in percentages \\
\hline BG-Lure & Hexanoic acid $73 \%$ \\
\hline \multirow[t]{6}{*}{ Volunteer $1,2 \& 3$ trunks } & Decanal (8\% -33\%) \\
\hline & Hexanal (8 - 32\%) \\
\hline & 6-methyl-5-hepten-2-one(15-28\%) \\
\hline & Nonanal (2 - 26\%) \\
\hline & Geranylacetone (3 - 13\%) \\
\hline & Hexanoic acid (4 - 9\%) \\
\hline \multirow[t]{6}{*}{ Volunteer $1,2 \& 3$ feet } & Hexanoic acid (7-36\%) \\
\hline & Octanal (3-18\%) \\
\hline & Nonanal (7 - 17\%), \\
\hline & Hexanal (3 -15\%) \\
\hline & 3-methylbutyric acid (7 - 9\%) \\
\hline & 2-methylpropionic acid (2-9\%) \\
\hline
\end{tabular}

anthropophillic and domesticated in behavior, where their life cycle transpires mainly inside and around human residences $[37,38]$. They are therefore more likely to be attracted to human odours than the inland populations of Busia. Furthermore, Ae aegypti mosquitoes have been observed to be highly adapted to urban rather than rural areas. They have a preference to rest inside houses and for areas with high human density, a behaviour that favours vector-human contact $[39,40]$. Therefore, as an urban area, a higher population density in Kilifi could have contributed to a higher abundance of Ae. aegypti.

Climatic differences between the two sites could also have contributed to the observed variation. Busia receives an average annual rainfall of $1500 \mathrm{~mm}$ and is cooler with a minimum temperature of $14^{\circ} \mathrm{C}$ and a maximum of $30^{\circ} \mathrm{C}$ compared to an average annual rainfall of $950 \mathrm{~mm}$ and higher temperatures with a minimum of $21^{\circ} \mathrm{C}$ and a maximum of $32^{\circ} \mathrm{C}$ in Kilifi. Previous studies reported that while adequate amounts of rain will create natural water bodies and fill artificial habitats, providing females with opportunities to lay their eggs, excessive rain may flush the immature stages, especially the eggs, from their habitats causing a population crash of Ae. aegypti [41]. It has also been observed that higher temperatures increased the developmental rate of Ae. aegypti [42], thus Kilifi which is relatively warmer than Busia would favour the breeding of higher densities of Ae. aegypti than Busia.

The traps baited with natural human odours from the feet and trunk, especially from volunteer 2 captured significantly more Ae. aegypti than the control trap baited with the synthetic commercial lure. Similar results were observed when the efficacy of the BG-sentinel trap baited with the commercial lure was compared with human landing/biting collections, a gas-powered $\mathrm{CO}_{2}$ trap, and a Fay-Prince trap, in monitoring adult populations of Ae. aegypti in field tests in the city of Belo Horizonte, Brazil [43]. Furthermore, human odours were found to be significantly more attractive than a synthetic three-component blend consisting of L-Lactic acid, acetone and dimethyl disulfide during competitive bioassays that simultaneously compared the attractiveness of Ae. aegypti to two treatments in a dual port olfactometer [26]. The presence of additional fatty acids such as 2methylpropionic acid and 3-methylbutyric acid, the four aldehydes; hexanal, octanal, nonanal and decanal and the two ketones 6-methyl-5-hepten-2-one and geranylacetone in human odours but not the BG-lure, suggests that these compounds likely played a role in the attractiveness of human odours over the BG-lure. Indeed, previous studies had shown that some of these compounds, including 2-methylpropionic acid, 3-methylbutyric acid, hexanal, octanal, nonanal and decanal are attractants of other mosquito species such as the malaria mosquito Anopheles gambiae [44,45] and mosquito vectors of Rift Valley Fever virus [21].

We found individual variation in the attractiveness of volunteers to mosquitoes based on our field captures. This observation is supported by our chemical analysis of volatiles collected from the different individuals, which showed qualitative and quantitative differences in specific components. This result is similar to previous studies of volatiles of mammalian odours in mosquito attraction $[46,47]$. For example, the difference in the attraction of different individuals to host seeking Ae. aegypti has been attributed to the difference in the quantity of lactic acid present on their skin [48]. Individuals with higher amounts of lactic acid on their skin attracted more mosquitoes, while adding lactic acid to the skin rubbings of individuals who were less attractive made them more attractive to mosquitoes. Inter-individual variation in body odour has also recently been attributed to the aggregation of different communities of micro biota on the skin. It has been demonstrated that individuals with lower bacteria diversity and with a significantly higher abundance of Leptotrichia spp., Delftia spp. and Actinobacteria Gp3 spp of bacteria on their skin are highly attractive to Anopheles gambiae s.s. while individuals with a higher microbial diversity and a higher abundance of Pseudomonas spp or Variovorax spp. of bacteria on their skin are poorly attractive [49].

The fact that traps baited with natural human skin odours collected significantly more male Ae. aegypti than the trap baited with the Biogent's lure is striking. This suggests that having a trap that is efficient in capturing male Ae. aegypti would help dengue and chikungunya fever control programs because it has been established that although male Ae. aegypti are not blood feeders they 
are usually infected with dengue and chikungunya viruses via transovarial transmission [50,51]. Recent studies document that male mosquitoes play an important role in the prevalence and maintenance of these diseases in the environment through venereal transmission of chikungunya virus from male to female Ae. Aegypti, which then transmits it to possible vertebrate hosts [52].

Lastly, the observation that traps baited with volatiles from the feet of volunteers not only captured more gravid Ae. aegypti than the control trap but also some blood fed ones increases their potential usefulness in dengue and chikungunya fever surveillance. Gravid mosquitoes are a high priority in arboviral surveillance programs. Conceivably, gravid mosquitoes would have already been exposed to virus infection through previous feeding, hence serving as likely indicators of virus activity [53]. On the other hand, blood-fed mosquitoes give information regarding the feeding preference, seroconversion status of that host, and infectivity level of the reservoir host, [54], which immensely helps researchers in understanding the ecology of arboviruses spread by mosquitoes. Additionally, testing of blood fed mosquitoes helps to understand the interaction mechanisms between host, vector and possible reservoirs, and to identify and evaluate the role of potential bridge vector species in transmission of pathogens of public health importance [55].

\section{Conclusions}

Our data indicate that traps baited with natural skin volatiles are more efficient than traps baited with the Biogent synthetic lure in sampling Ae. aegypti. However, the efficacy of human odours varies between individuals $[47,56,57]$ and hence causes variation in trap captures. Additional studies will be required to determine the specific compound(s) that increase the attractiveness of human odours and subsequent trap captures for development and evaluation.

\section{Competing interests}

The authors declare that they have no competing interests.

\section{Authors' contributions}

EAO RS BT conceived and designed experiments. EAO conducted the experimental work. EAO analyzed the data. EAO RS CLS CPL CM BT wrote the manuscript. All authors approved the final version for submission.

\footnotetext{
Acknowledgments

We thank James Wauna of The International Centre of Insect Physiology and Ecology (ICIPE), who helped with field sampling and Festus Yaah of Kenya Medical Research Institute (KEMRI) -Kilifi, who helped with mosquito identifications.

Our immense gratitude to the Kenya Medical Research Institute (KEMRI) Kilifi and Busia and especially to Dr Matilu Mwau, the director of KEMRI, Busia who provided laboratory space for sorting and identification of the mosquito species.

I would also like to express my gratitude to the Swedish International Development Cooperation Agency (Sida) for funding my studentship at ICIPE.
}

\section{Author details}

'International Centre of Insect Physiology and Ecology, P.O BOX 30772-00100, Nairobi, Kenya. ${ }^{2}$ Department of Zoology and Entomology, University of Pretoria, Pretoria, South Africa. ${ }^{3}$ Centre for Virus Research, Kenya Medical Research Institute, Nairobi, Kenya. ${ }^{4}$ Centre for Geographic Medicine Research - Coast, KEMRI \& KEMRI - Wellcome Trust Research Programme, Kilifi, Kenya.

Received: 11 June 2014 Accepted: 15 September 2014 Published: 23 September 2014

\section{References}

1. Gubler DJ: Dengue. In The Arboviruses: Epidemiology and Ecology, vol 2 Edited by Monath TP. Boca Raton, Florida: CRC Press; 1989:223-260.

2. Halstead SB, Nimmannitya S, Yamarat C, Russell PK: Hemorrhagic fever in Thailand; recent knowledge regarding etiology. Jpn J Med Sci Biol 1967, 20:96-103.

3. Monath TP: Yellow fever. In The Arboviruses: Epidemiology and Ecology, vol 5. Edited by Monath TP. Boca Raton, Florida: CRC Press; 1989:139-231.

4. Gubler DJ: The global emergence/resurgence of arboviral diseases as public health problems. Arc Med Res 2002, 33:330-342.

5. Gubler DJ: Dengue and dengue hemorrhagic fever: its history and resurgence as a global public health problem. In Dengue and Dengue Hemorrhagic Fever. Edited by Gubler DJ, Kuno G. CAB International, London, United Kingdom: WHO; 1997:1-22.

6. World Health Organization: Report of the scientific working group on dengue. In Special Programme for Research and Training in Tropical Diseases. Switzerland, Geneva: World Health Organization; 2006:1.

7. World Health Organization: Guidelines for diagnosis, treatment, prevention and control. In Dengue. Switzerland, Geneva: World Health Organization; 2009:3.

8. Powers $\mathrm{AM}$, Logue $\mathrm{CH}$ : Changing patterns of Chikungunya virus: reemergence of a zoonotic arbovirus. J Gen Virol 2007, 88:2363-2377.

9. Sergon K, Njuguna C, Kalani R, Ofula V, Onyango C, Konongoi LS, Bedno S, Burke H, Dumilla AM, Konde J: Seroprevalence of Chikungunya virus (CHIKV) infection on Lamu Island, Kenya, October 2004. Am J Trop Med Hyg 2008, 78:333-337.

10. Chretien JP, Anyamba A, Bedno SA, Breiman RF, Sang R, Sergon K, Powers AM, Onyango CO, Small J, Tucker CJ, Linthicum KJ: Drought associated Chikungunya emergence along coastal East Africa. Am J Trop Med Hyg 2007, 76:405-407.

11. Sang RC, Ahmed O, Faye O, Kelly CL, Yahaya AA, Mmadi I, Toilibou A, Sergon K, Brown J, Agata N, Yakouide A, Ball MD, Breiman RF, Miller BR, Powers AM: Entomologic investigations of a Chikungunya virus epidemic in the union of the Comoros 2005. Am J Trop Med Hyg 2008, 78(1):77-82.

12. State-confirms-outbreak-of-dengue-fever-in-mandera. [http://www. standardmedia.co.ke/?articlelD=2000043805\&story_title=state-confirmsoutbreak-of-dengue-fever-in-mandera]

13. Coast region hit by mosquito transmitted fever. [http://www. standardmedia.co.ke/mobile/?articlelD=2000121930\&story_title=coastregion-hit-by-mosquito-transmitted-fever]

14. Beatty ME, Letson GW, Margolis HS: Estimating the global burden of dengue. In Abstract Book: Dengue. The Second International Conference on Dengue and Dengue Haemorrhagic Fever. Phuket, Thailand: 2008. (As cited in: Gubler DJ. Dengue, urbanization and globalization: the unholy trinity of the 21st century. Trop Med Health. 2011, 39(4):3-11.

15. Alirol E, Getaz L, Stoll B, Chappuis F, Loutan L: Urbanization and infectious disease in a globalized world. Lancet Infect Dis 2009, 10:131-141.

16. Enserink M: Infectious diseases: Chikungunya: no longer a third world disease. Sci 2007, 318(5858):1860-1861.

17. Service M W: Mosquito Ecology: Field-sampling Methods. 2nd edition. London: Chapman \& Hall; 1993.

18. Focks DA: A review of entomological sampling methods and indicators for dengue vectors. In Special Programme for Research and Training in Tropical Diseases. Geneva, Switzerland: WHO; 2003.

19. Sudia WR, Chamberlain W: Battery operated light trap, an improved model. Mosa News 1962, 22:126-129.

20. Tchouassi DP, Sang R, Sole CL, Bastos ADS, Mithoefer K, Torto B: Sheep skin odor improves trap captures of mosquito vectors of rift valley fever. PLoS Negl Trop Dis 2012, 6:e1879.

21. Tchouassi DP, Sang R, Sole CL, Bastos ADS, Teal PEA, Borgemeister C, Torto B: Common host-derived chemicals increase catches of disease-transmitting 
mosquitoes and can improve early warning systems for rift valley fever virus. PLoS Negl Trop 2003, 7(1):1-11.

22. Geier M, Rose A, Grunewald J, Jones O: New mosquito traps improve the monitoring of disease vectors. Int Pest Control 2006, 48:124-126.

23. Canyon DV, Hii JLK: Efficacy of carbon dioxide, 1-octen-3-ol, and lactic acid in modified Fay-Prince traps as compared to man-landing catch of Aedes aegypti. J Am Mosa Control Assoc 1997, 13:66-70.

24. Jones JW, Sithiprasasna R, Schleich S, Coleman RE: Evaluation of selected traps as tools for conducting surveillance for adult Aedes aegypti in Thailand. J Am Mosa Control Assoc 2003, 19:148-150.

25. Schoeler GB, Schleich SS, Manweiler SA, Sifuentes VL: Evaluation of surveillance devices for monitoring Aedes aegypti in an urban area of northeastern Peru. J Am Mosa Control Assoc 2004, 20:6-11.

26. Bernier UR, Kline DL, Allan SA, Barnard DR: Laboratory comparison of Aedes aegypti attraction to human odors and to synthetic human odor compounds and blends. J Am Mosa Control Assoc 2007, 23(3):288-293.

27. Mease LE, Coldren RL, Musila LA, Prosser T, Ogolla F, Ofula VO, Schoepp RJ, Rossi CA, Adungo N: Seroprevalence and distribution of arboviral infections among rural Kenyan adults: a cross-sectional study. Virol J 2011, 8:371.

28. Edwards FW: Mosquitoes of the Ethiopian Region III. London, United Kingdom: London British Museum of Natural History; 1941.

29. Gillies MT, DeMeillon B: The Anophelinae of Africa South of the Sahara (Ethiopian Zoogeographical Region). 2nd edition. Johannesburg, South Africa: South African Institute of Medical Research; 1968.

30. Huang YM, Ward RA: A pictorial key for the identification of the mosquitoes associated with yellow fever in Africa. Mosq Systematic 1981 13(2):138-149.

31. Rueda LM: Pictorial keys for the identification of mosquitoes (Diptera; Culicidae) associated with dengue virus transmission. Zoo Taxa 2004, 589:1-60.

32. World Health Organization: Malaria entomology and vector control. In Learner's Guide. 2003:42-43.

33. Core Team R: A Language and Environment for Statistical Computing. $R$ Foundation for Statistical Computing. Vienna, Austria: URL http://www.Rproject.org/ 2014.

34. Christophers SR: Aedes aegypti (L.), the Yellow Fever Mosquito: its Life History, Bionomics and Structure. Cambridge, United Kingdom: Cambridge University Press; 1960.

35. Southwood TRE, Murdie G, Yasuno M, Tonn RJ, Reader PM: Studies on the life budget of Aedes aegypti in Wat Samphaya, Bangkok, Thailand. Bull World Health Organ 1972, 46:211-226.

36. Walker KR, Joy TK, Ellers-KIrk C, Ramberg FB: Human and environmental factors affecting Aedes aegypti distribution in an arid urban environment. J Am Mosa Control Assoc 2011, 27(2):135-141.

37. Tabachnick WJ, Powell JR: Genetic structure of the East African domestic populations of Aedes aegypti. Nature 1978, 272(5653):535-537. PubMed PMID.

38. McDonald PT: Population characteristics of domestic Aedes aegypti (diptera: culicidae) in villages on the Kenya coast. II. Dispersal within and between villages. J Med Entomol 1977, 14(1):49-53. PubMed PMID: 903936.

39. Lima-Camara TN, Honório NA, Lourenço-de-Oliveira R: Frequency and spatial distribution of Aedes aegypti and Aedes albopictus (Diptera, Culicidae) in Rio de Janeiro, Brazil. J Pub Health 2006, Print version ISSN 0102-311X.

40. Tsuda Y, Suwonkerd W, Chawprom S, Prajakwong S, Takagi M: Different spatial distribution of Aedes aegypti and Aedes albopictus along an urban rural gradient and the relating environmental factors examined in three villages in northern Thailand. J Am Mosa Control Assoc 2006, 22:222-228.

41. Koenraadt CJ, Harrington LC: Flushing effect of rain on containerinhabiting mosquitoes Aedes aegypti and Culex pipiens (Diptera: Culicidae). J Med Entomol 2008, 45(1):28-35.

42. Yusoff N, Budin H, Ismail S: Simulation of population dynamics of Aedes aegypti using climate dependent model. A W Acad Sci, Eng Tech 2012, 6(2):477.

43. Kröckel U, Rose A, Eiras AE, Geier M: New tools for surveillance of adult yellow fever mosquitoes: comparison of trap catches with human landing rates in an urban environment. J Am Mosa Control Assoc 2006, 22:229-238.

44. Mukabana WR, Mweresa CK, Otieno B, Omusula P, Smallegange RC, Van Loon JAJ, Takken W: A novel synthetic odorant blend for trapping of malaria and other African mosquito species. J Chem Ecol 2012, 38:235.
45. Nyasembe VO, Teal PEA, Mukabana WR, Tumlinson J, Torto B: Behavioural response of the malaria vector Anopheles gambiae to host plant volatiles and synthetic blends. Parasit Vectors 2012, 5:234.

46. Lindsay SW, Adiamah JH, Miller J: Variation in attractiveness of human subjects to malaria mosquitoes (Diptera: Culicidae) in the Gambia. J Med Entomol 1993, 30:368-373.

47. Knols BGJ, De Jong R, Takken W: Differential attractiveness of isolated humans to mosquitoes in Tanzania. Trans R Soc Trop Med Hyg 1995, 89:604-606

48. Geier M, Sass H, Boeckh J: A Search for Components in Human Body Odors that Attract Females of Aedes aegypti. Ciba Foundation Symposium 200. New York: John Wiley \& Sons; 1996:132-144.

49. Verhulst NO, Qiu YT, Beijleveld H, Maliepaard CA, Knights D, Schulz S, Berg-Lyons D, Lauber CL, Verduijn W, Haasnoot GW, Mumm R, Bouwmeester HJ, Claas FHJ, Dicke M, JJA V I, Takken W, Knight R, Smallegange RC: Composition of human skin micro biota affects attractiveness to malaria mosquitoes. PLoS One 2011, 6:e28991.

50. Thenmozhi V, Tewari SC, Manavalan R, Balasubramanian A, Gajanana A: Natural vertical transmission of dengue viruses in Aedes aegypti in southern India. Trans R Soc Trop Med Hyg 2000, 94:507.

51. Thavara U, Tawatsin A, Pengsakul T, Bhakdeenuan P, Chanama S, Anantapreecha S, Molito C, Chompoorsri J, Thammapalo S, Sawaboabyakert $\mathrm{OM}$, Siriyasatien P: Outbreak of chikungunya fever in Thailand and virus detection in field population of vector mosquito Aedes aegypti and Aedes albopictus. J Trop Med Public Health 2009, 40:951-962.

52. Mavale M, Parashar D, Sudeep A, Gokhale M, Ghodke Y, Geevarghese G, Arankalle V, Chandra AM: Venereal transmission of chikungunya virus by Aedes aegypti mosquitoes. Am J Trop Med Hyg 2010, 83(6):1242-1244.

53. Allan BF, Goessling LS, Storch GA, Thach RE: Blood meal analysis to identify reservoir hosts for Amblyomma americanum ticks. Emerg Infect Dis 2010, 16(3):433-440.

54. Kay BH, Boyd AM, Ryan PA, Hall RA: Mosquito feeding patterns and natural infection of vertebrates with Ross river and Barmah forest viruses in Brisbane, Australia. Am J Trop Med Hyg 2007, 76:417-423.

55. Reiter P: A portable battery-powered trap for collecting gravid Culex mosquitoes. Mosq News 1983, 43:496498.

56. Logan JG, Birkett AM, Clark SJ, Powers S, Seal NJ, Wadhams LJ, Mordue AJ Pickett JA: Identification of human-derived volatile chemicals that interfere with attraction of Aedes aegypti mosquitoes. J Chem Ecol 2008, 34:308-322.

57. Schreck $C E$, Kline DL, Carlson DA: Mosquito attraction to substances from the skin of different humans. J Am Mosa Control Assoc 1990, 6:406-410.

doi:10.1186/1756-3305-7-451

Cite this article as: Owino et al: Field evaluation of natural human odours and the biogent-synthetic lure in trapping Aedes aegypti, vector of dengue and chikungunya viruses in Kenya. Parasites \& Vectors 2014 7:451.

\section{Submit your next manuscript to BioMed Central and take full advantage of:}

- Convenient online submission

- Thorough peer review

- No space constraints or color figure charges

- Immediate publication on acceptance

- Inclusion in PubMed, CAS, Scopus and Google Scholar

- Research which is freely available for redistribution 